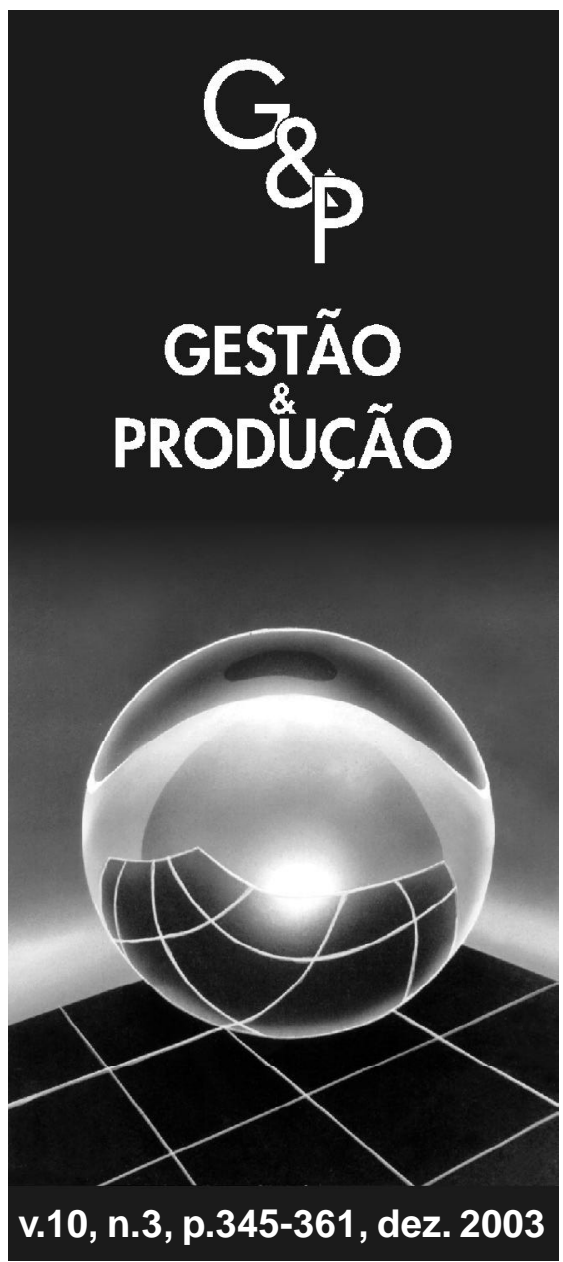

\title{
REFLEXÃO PARA GESTÃO TECNOLÓGICA EM CADEIAS DE SUPRIMENTO
}

\author{
Maria Rita Pontes Assumpção \\ Departamento de Engenharia de Produção, \\ Universidade Federal de São Carlos, C.P. 676, \\ CEP 13565-905, São Carlos, SP, \\ e-mail:dmrp@power.ufscar.br
}

Recebido em 27/6/2003

Aceito em 26/11/2003

\section{Resumo}

Estudos sobre adoção de tecnologia na cadeia de suprimentos são mais intensamente relacionados às novas tecnologias de informação e comunicação (TIC) e a seu impacto nos processos de negócios nos canais de distribuição. Este trabalho amplia essa análise para refletir sobre inovação no produto transacionado ou serviço ofertado, focando na relação fornecedor-fabricante. As questões colocadas para essa reflexão são: como as empresas constroem o novo arranjo produtivo decorrente dessas mudanças? Como as empresas coordenam o desenvolvimento de novo produto ou serviço na relação fornecedor $\times$ comprador/fabricante? $O$ artigo conceitua arquitetura interorganizacional como uma estrutura para organização do novo arranjo das empresas diante dessas mudanças. É sob essa estrutura que as empresas conjuntamente poderão construir os novos processos de decisão sobre locação e uso da capacidade produtiva (recursos tecnológicos) e de coordenação (gestão das atividades de interface entre as empresas) para terem operações mais efetivas e maior rapidez para atender aos eventos da cadeia de suprimento.

Palavras-chave: cadeia de suprimentos, gestão tecnológica, organização. 


\section{Introdução}

$\mathrm{T}$ radicionalmente, o foco dos gerentes de empresas de manufatura era diminuir custos na compra de insumos e em gastos operacionais, considerando suas próprias capacitações. Com a visão da cadeia de valor da empresa, o foco é centrado em suas atividades essenciais. Essas atividades são aquelas que a empresa tem competência para desempenhar, seja pela produtividade em suas operações ou porque a tecnologia utilizada é própria e ainda não é de senso comum. As demais atividades são terceirizadas, sendo da responsabilidade de parceiros de negócios, cujas operações são subordinadas por coordenação daquele que tem poder para isso. Esses parceiros, por sua vez, têm competência para atuar nessas atividades, que para eles são essenciais, considerando a cadeia de valor estendida de seus produtos.

O funcionamento das empresas sob essa lógica motivou a abordagem de gestão de cadeias de suprimento (GCS: Supply Chain Management $\mathrm{SCM})$, cujo princípio básico é assegurar maior visibilidade dos eventos relacionados à satisfação da demanda, com o objetivo de minimizar os custos das operações produtivas e logísticas entre as empresas, constituintes do fluxo de materiais, componentes e produtos acabados (Christopher, 1997; Handfield \& Nichols, 1999; Chopra \& Meindel, 2003).

O modelo para gestão da cadeia de suprimento mais recorrente na literatura, apresentado em Lambert \& Cooper (2000), prevê a gerência de sete processos de negócios entre as empresas, como apresentado na Seção 2.3.2. Considerando que esse modelo não explicita como gerenciar as mudanças organizacionais e tecnológicas decorrentes de inovação de produto e/ou processo, este artigo tem por objetivo refletir sobre essa questão. Essa reflexão, desenvolvida na Seção 2, leva à proposição de um modelo conceitual para gestão dessas transformações no ambiente de cadeia de suprimento (CS), apresentado na Seção 3. Também nessa seção é proposta uma estrutura para organizar a colaboração entre fornecedores e fabricantes, no caso de mudança do produto transacionado. O artigo finaliza apresentando algumas considerações para aplicação do modelo proposto.

\section{Gestão da cadeia de suprimento}

Estudos em gestão da cadeia de suprimento enfatizam a importância de relações estratégicas entre empresas de manufatura e seus fornecedores (Kim, 2000; Petroni \& Panciroli, 2002). A hipótese que fundamenta a ênfase nesse aspecto é a de que relacionamentos de longo prazo melhoram o desempenho tanto do fabricante quanto de seus fornecedores. Para esse tipo de relacionamento é essencial a coordenação de ações entre os parceiros de negócios. Malone \& Crowston (apud Kim, 2000) definem coordenação como o processo de gerenciar dependências entre atividades, considerando aspectos como: compartilhamento de recursos (humanos, informacionais e físicos), designação de tarefas, desenvolvimento de relacionamento entre as empresas, entre outros.

Alguns autores visam a estudar mecanismos de coordenação, sendo que a maioria indica a necessidade de ter uma estrutura para desenvolvimento de ações conjuntas (Fisher, 1997; Heikkilä, 2002; Hagelaar \& van der Vorst, 2002). Com informações que dão visibilidade aos eventos na rede de empresas é mais fácil discenir sobre a decisão correta a ser tomada no empreendimento dessas ações (Anand \& Mendelson, 1997; GarcíaDastugue \& Lambert, 2003).

Fisher (1997) nota que essa estrutura deve se diferenciar conforme o produto, seja funcional (demanda estável e ciclo mais longo de vida do produto) ou inovador (demanda instável e obsolescência rápida). No primeiro tipo, a coordenação deve ter por objetivo diminuir custos logísticos, buscando a racionalidade nas operações de transporte e armazenagem. No segundo tipo, o objetivo é reduzir custos de mediação ao mercado, buscando gerenciar a incerteza com processos que garantam que a variedade correta de produtos seja associada a canais de distribuição que os tornem disponíveis para a compra no momento adequado. Assim, se terá uma cadeia eficiente para produtos funcionais e uma 
cadeia responsiva aos produtos inovadores. Heikkilä (2002) exemplifica essa situação para telefonia móvel (celulares).

Hagelaar \& van der Vorst (2002) apresentam diferentes estruturas para adoção de estratégias distintas para gestão ambiental na cadeia de suprimento. Esses autores notam que, à medida que aumenta o comprometimento da estratégia da cadeia de suprimento com a sustentabilidade ambiental, é necessária uma estrutura mais complexa de relacionamento entre as empresas (quanto às funções que são compartilhadas e ao maior número de consultas entre os membros da cadeia de suprimento).

Essas propostas prevêem o desenvolvimento de fornecedores e agentes de canais de distribuição, e visam à gestão da demanda (e do fluxo produtivo para atendê-la), conforme meta estabelecida de comum acordo. A despeito disso, nenhuma delas apresenta explicitamente estrutura para desenvolvimento de novas capacitações, necessárias na presença de inovação tecnológica, seja em recurso (produto), seja em atividade (processo). Assim, considera-se que essas propostas não são suficientes para gerenciar as transformações decorrentes das inovações.

\subsection{Rede industrial}

O referencial teórico para análise das inovações organizacionais e tecnológicas que se dão em redes de empresas parte do pressuposto de que mudança tecnológica e desempenho competitivo estão interligados, segundo uma visão sistêmica, apoiando a capacitação produtiva das empresas. Redes industriais (categoria genérica da cadeia de suprimento) são vistas como arranjos para integração operacional, considerando o desempenho de ciclos de atividades, vistos como processos.

Lundgren (1995, p. 87) define rede industrial como constituída de “...atores ligados por seu desempenho em torno de atividades industriais competitivas ou complementares, empregando ou consumindo recursos econômicos para processar outros recursos"; e reproduz modelo, originalmente apresentado por Häkansson (1987, apud Lundgren, 1995, p. 88), para análise das mudanças tecnológicas em redes industriais (Figura 1).

A rede industrial é considerada composição de dois conjuntos básicos de ligações entre suas atividades (Lundgren, 1995):

- conjunto institucional: as regras que regem as trocas entre os sistemas de produção e os existentes nos canais de distribuição/ fornecimento;

- conjunto tecnológico: constituído pelos sistemas de produção, ligando recursos e sistemas tecnológicos, segundo i) uma lógica industrial, que define a natureza das atividades de produção e de distribuição/ fornecimento, e ii) o conhecimento da tecnologia do produto, dos métodos de produção e dos recursos trocados entre as empresas.

Lundgren (1995) aponta que os atores de uma rede industrial possuem grau mínimo de autonomia para controle de recursos e/ou atividades, embora seus processos sejam interdependentes. Os recursos transacionados são complementares e podem ser tangíveis, como capital e terra ou quaisquer outros materiais que sirvam de insumos, ou intangíveis, como conhecimento, competências (capacitações) e habilidades.

Os ciclos de atividades apóiam os processos de negócios (cadeia de transações) para transformação e troca de materiais e produtos, constituindo atividades de produção e logística. $\mathrm{O}$ sincronismo entre essas atividades depende da estrutura de coordenação da cadeia de suprimento, embora todas as atividades sejam interligadas.

Os conjuntos tecnológico e institucional criam interdependências entre os atores da rede, embora se deva garantir identidade e legitimidade aos papéis que cada um desempenha. Por essa razão "a estrutura da rede e o padrão de comportamento institucionalizado afetam as possibilidades de mudanças no sistema tecnológico" (Lundgren, 1995, p. 96). 


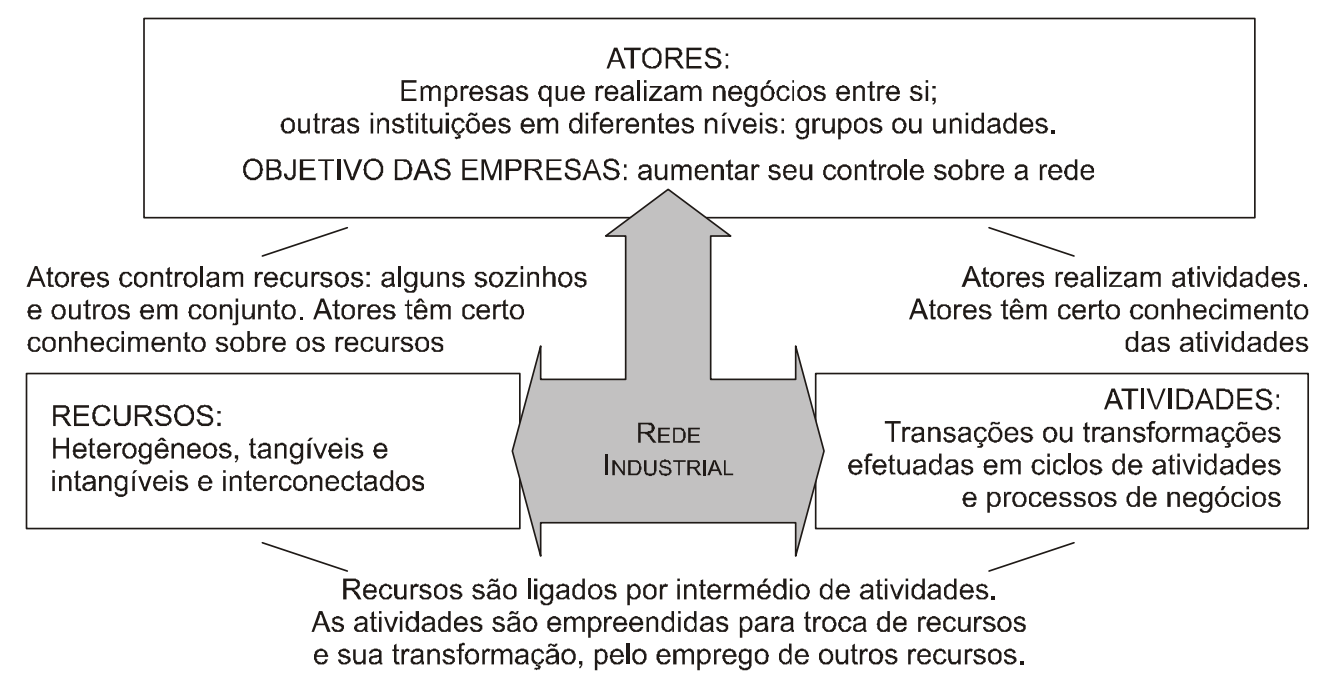

Figura 1 - Redes industriais. Fonte: Adaptada de Häkansson (apud Lundgren, 1995, p. 88).

O conjunto tecnológico é constituído pelos artefatos dos sistemas de produção e para troca de recursos (rede logística). Os atores individuais dependem dos demais na realização de suas atividades para produção e uso de recursos. A mudança tecnológica pode interferir na especialização e na divisão do trabalho entre as empresas, mudando o papel de cada uma na rede industrial. Por essa razão, é necessário definir novo arranjo para a rede industrial transformada. $\mathrm{O}$ conjunto institucional é resultado da interação entre os atores, sendo que nenhum ator controla todos os recursos transacionados nem é responsável pela execução de todas as atividades complementares nas interfaces ou na cadeia de transações. Esse é outro argumento para a construção de estrutura para definir as novas regras que vigorarão na rede industrial transformada.

\subsection{Visibilidade de eventos e agilidade para mudanças}

Slack et al. (2002) usa o termo cadeia de suprimento (supply chain) para designar um ramo da rede industrial com estrutura projetada adequadamente para atender à demanda de um mer- cado específico. O conceito de rede de suprimento, definido em Slack (1993), pressupõe a adoção coordenada de estratégias de manufatura entre parceiros de negócios.

Esses conceitos preencheram lacuna identificada por Bechtel \& Jayaram (1997). Esses autores observaram que os esforços para aumentar a produtividade industrial e a qualidade de processos e produtos de uma empresa eram dificultados por restrições da empresa para integração de suas estratégias de operações, internamente, com outras funções (marketing finanças, principalmente), e externamente, com seus clientes e fornecedores.

Os estudos de logística consideram que essa dificuldade pode ser suplantada pela coordenação da rede de empresas que participam da conformação do produto que será levado ao mercado para realização de seu valor. Essa coordenação direciona a gestão de processos de negócios entre as empresas da cadeia de suprimento, cuja meta é servir ao consumidor final na medida necessária e no tempo certo, ao menor custo. Segundo Porter (1986), é necessário gerenciar os elos da cadeia de valor constituída por esses processos, reduzindo ou retirando atividades que não 
agreguem valor ao produto e construindo ou reformulando outras que possam adicionar ainda mais valor para o consumidor final. Essa argumentação de Porter firma o conceito de cadeia de suprimento e os princípios que regem sua gestão: aumentar a visibilidade dos eventos a todos os participantes da cadeia de suprimento para gestão mais efetiva da demanda.

Esses princípios apresentam similaridades com os do conceito de funcionamento em fluxo tenso, encontrado nos estudos sobre cadeias agroalimentares e de alimentos processados (Green \& Santos, 1991). No funcionamento em fluxo tenso busca-se capacitação para redução do ciclo de desenvolvimento de novos produtos, além de competência para visualizar ocorrências em todos os elos da cadeia. Para redução do ciclo de desenvolvimento de novos produtos, Ragatz et al. (1997) e Marques (1999) apontam a necessidade de estreitar o relacionamento entre fornecedores e fabricantes.

Os dois conceitos (fluxo tenso e cadeia de suprimento) emergem das novas práticas gerenciais, facilitadas pela adoção da tecnologia de informação e comunicação. As TIC agilizam a captação e o tratamento dos dados, a produção de conhecimento pelo uso das mesmas e a comunicação on-line entre parceiros de negócios. Porém, essas facilidades não são suficientes para coordenação da cadeia de suprimento, em razão da complexidade em gerenciar valores e interesses distintos entre as empresas participantes de uma rede industrial.

A necessidade de agilizar o ciclo de desenvolvimento de novos produtos e a tendência a compartilhar essa atividade na rede de empresas são mais um ponto para reforçar a necessidade de construção da estrutura para gerenciar as mudanças tecnológicas e organizacionais na cadeia de suprimento. Ragatz et al. (1997) demonstram que, quanto mais cedo for estabelecida a integração entre clientes industriais e fornecedores no projeto de novos produtos, mais efetiva será a redução nos custos e no tempo de desenvolvimento dos mesmos. Handfield \& Nichols (1999), por outro lado, reconhecem a importância do alinhamento das estratégias das empresas com a da cadeia de suprimento para melhoria do desempenho na relação entre fornecedores e clientes industriais. Esse alinhamento proporciona habilidades para melhoria de desempenho da empresa, desde que haja: clareza na visão de seu papel na cadeia de suprimentos; e realização conjunta de atividades de aprendizado e inovação. Segundo Terra (2000), essa é uma prática dos kyoeikai - Associação para Prosperidade Mútua -, desenvolvida por grupo de fornecedores e que constitui importante veículo de aprendizagem para empresas japonesas, assim como o é a manutenção de equipes de pessoas de diferentes empresas, parceiras no outsourcing (para assimilar parcela do conhecimento tácito que a outra possui).

\subsection{Estrutura da cadeia de suprimento}

A estrutura reflete as relações entre as empresas da cadeia de suprimento. O desenvolvimento de relacionamento efetivo entre as empresas da cadeia de suprimento contribui para a melhoria do desempenho das operações nas dimensões: qualidade, custo, entrega e flexibilidade (Slack, 1993).

O Quadro 1 sintetiza resultados de revisão bibliográfica sobre aspectos relevantes de relações entre empresas, que moldam o ambiente de decisão e de operações e definem a profundidade e a estreiteza do relacionamento, assim como sua duração e amplitude.

A estrutura da cadeia de suprimento é conformada por duas dimensões: complexidade do relacionamento e número de consultas entre as empresas (Quadro 2).

Hagelaar \& van der Vorst (2002) apresentam quatro tipos de cooperação na cadeia de suprimento, conforme as dimensões anteriores, reproduzidos na Figura 2. 


\section{Quadro 1 - Fatores críticos de sucesso nas parcerias entre empresas.}

Adaptado de Hagelaar \& van der Vorst (2002).

\begin{tabular}{|c|c|c|}
\hline Orientadores & Facilitadores & Parcerias de sucesso \\
\hline \multirow{2}{*}{$\begin{array}{l}\text { Eficiência dos ativos (redução } \\
\text { de custos) }\end{array}$} & Complementaridade estratégica & Planejamento colaborativo \\
\hline & Programação cooperativa & Controle de operações na cadeia de \\
\hline \multirow{4}{*}{$\begin{array}{l}\text { Serviço ao cliente (redução de } \\
\text { tempo nos ciclos de } \\
\text { atividades; diferenciação de } \\
\text { produtos/serviços) }\end{array}$} & Compatibilidade/sinergia & suprimentos \\
\hline & cultural e de atitudes & Compartilhar benefícios e riscos \\
\hline & Filosofia e técnicas gerenciais & Confiança e comprometimento mútuos \\
\hline & Troca mútua (objetivos comuns, & Extensão (alianças de longo prazo) \\
\hline $\begin{array}{l}\text { Vantagem de marketing } \\
\text { (novos mercados) }\end{array}$ & $\begin{array}{l}\text { compartilhar informação } \\
\text { sensitiva) }\end{array}$ & $\begin{array}{c}\text { Ocorrência de "pontes" de } \\
\text { comunicação }\end{array}$ \\
\hline $\begin{array}{l}\text { Estabilidade/crescimento } \\
\text { nos lucros }\end{array}$ & $\begin{array}{l}\text { Simetria de poder (resolução de } \\
\text { conflitos de interesses) }\end{array}$ & $\begin{array}{l}\text { Processos de aprendizagem para } \\
\text { desenvolvimento de capacitação }\end{array}$ \\
\hline
\end{tabular}

\section{Quadro 2 - Aspectos a serem considerados para gestão da cadeia de suprimento.}

A extensão na complexidade do relacionamento entre as empresas é definida pelo número de funções incluídas para esforços conjuntos (marketing, logística, desenvolvimento de produtos, políticas de preservação ambiental, etc.)

A forma de influência na decisão é definida como o número de consultas entre as empresas que influenciam a tomada de decisão

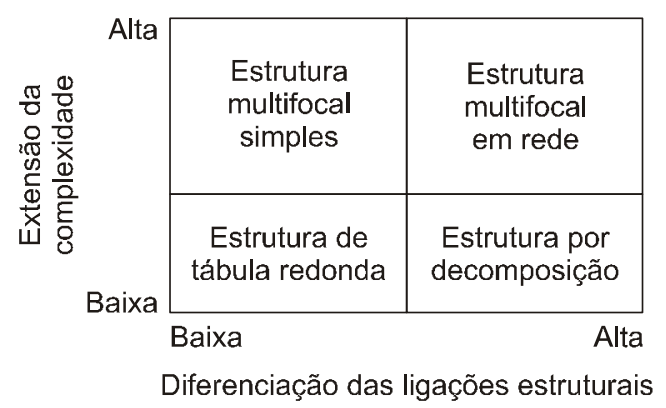

Figura 2 - Tipologia de estruturas de cooperação na cadeia de suprimento. Fonte: Hagelaar \& van der Vorst (2002).

$\mathrm{Na}$ estrutura do tipo tábula redonda ocorrem poucas consultas para decisão conjunta; as decisões são focadas em uma única função e as demais são tratadas separadamente por empresa, individualmente. Na estrutura multifocal simples são poucas as consultas entre os parceiros, embora participem conjuntamente nos processos de decisão em várias funções. As decisões internas na empresa são afinadas com as decisões tomadas em conjunto. A estrutura de decomposição é caracterizada por um número limitado de funções submetidas à decisão conjunta, porém há consulta sobre outras funções entre os parceiros de negócios. A estrutura multifocal em rede é conveniente no caso de a decisão conjunta referir-se a muitas funções, mas com processos de tomada de decisão diferenciados, conforme a função e a meta. Os mecanismos de coordenação 
nesse tipo de estrutura são: equipes-tarefa, interfaces entre diferentes funções (internamente e entre as empresas) e gestão de alianças ou comitê gestor. As decisões podem ser centralizadas ou descentralizadas, enquanto há decomposição dos problemas em áreas ou funções. As últimas configurações (decomposição e multifocal em rede) são mais adequadas em parcerias que envolvam mudanças tecnológicas.

\subsubsection{Estrutura e desempenho da cadeia de suprimento}

Slack et al. (2002) definem "política da cadeia de suprimento como a forma pela qual as operações na cadeia influenciam seu comportamento" e apontam a administração dos relacionamentos como uma das questões-chave para gestão efetiva da cadeia de suprimento (Slack $e t$ al. 2002, p. 436). Os autores caracterizam a cadeia de suprimento como sistema dinâmico, em que as decisões são orientadas por políticas deliberadas em função do desempenho esperado.

Um dos primeiros autores a apresentar essa preocupação foi Fisher (1997), que propôs estrutura para organização da cadeia de suprimento de acordo com a natureza da demanda (estável ou volátil) e as características do produto (funcional ou inovador). Na situação de demanda estável, em que é possível prever a demanda de produtos acabados, programa-se a disponibilidade para oferta (processo push). No caso de vulnerabilidade na demanda, os componentes devem estar disponíveis para montagem do produto assim que despontar a necessidade de atendimento, evitando o custo da nãovenda, incorrido pela obsolescência do produto (processo pull). Políticas que busquem a eficiência são apropriadas a produtos funcionais com demanda estável. O controle de estoques mantém níveis baixos nos canais de distribuição, embora com aceleração do tempo de ciclo de pedidos para reposição dos produtos nos pontos-de-venda. É alto o uso da capacidade produtiva, com vistas a reduzir os custos de produção, dada a baixa margem de lucro associada a esse tipo de produto. As informações de mercado devem fluir para ajuste rápido da programação da produção, minimizando o efeito bullwhip (Forrester) (Handfield \& Nichols, 1999). Esse efeito produz amplificação de erros no cálculo da demanda dependente, a qual reflete os requisitos para os processos produtivos. Cadeias de suprimento caracterizadas por demanda volátil e produtos inovadores são orientadas por políticas responsivas que enfatizam altos níveis de serviço ao consumidor. Há necessidade de agilizar o ciclo de planejamento das atividades no canal de fornecimento, a fim de compor variedade de produtos para atender à demanda explicitada. A base do relacionamento com fornecedores é constituída pelos atributos flexibilidade e velocidade na montagem final do produto. $\mathrm{O}$ volume de capital comprometido com estoques é situado a montante, antes de seu comprometimento com a personalização do produto final.

\subsubsection{Considerações sobre o modelo de Lambert \& Cooper para GCS}

O modelo de Lambert \& Cooper (2000) considera três elementos para gestão da cadeia de suprimento: processos de negócios, componentes de gestão e estrutura (Figura 3).

Os componentes de gestão potencializam o uso da estrutura da cadeia de suprimento para a eficácia nos processos de negócios. Assim, também os recursos tecnológicos limitam os níveis de eficiência nos fluxos de informação e físico e, conseqüentemente, o nível de sucesso dos negócios entre as empresas. Os processos de negócios são descritos na Tabela 1.

\subsection{Integração com fornecedores}

Segundo McGee \& Pruzak (1994), a competência da empresa em responder rapidamente a mudanças é reflexo de sua capacidade de alinhar o planejamento estratégico com seu desempenho operacional. Teece et al. (1997) apresentam casos de como as empresas coordenam suas rotinas e capacitações para obter desempenho em custo, qualidade e velocidade. Esses autores destacam 
a dificuldade para reconfigurar um sistema produtivo na presença de mudanças, requerendo transformação interna, e nas ligações interorganizacionais. Mesquita \& Alliprandini (2003) verificam que, embora as competências para melhoria contínua da produção estejam presentes em empresas da indústria brasileira automotiva, nenhuma atividade é conduzida para geri-las. O gerenciamento estratégico da informação fundamenta $o$ processo de aprendizagem organizacional e o desenvolvimento de novas habilidades individuais para esse alinhamento.
No ambiente de rede industrial, o processo interorganizacional de aprendizagem é mais complexo do que quando está restrito internamente a uma firma. Nesse ambiente, os ativos organizacionais invisíveis e intangíveis (marca, conhecimento sobre produto e processos, lealdade do cliente, etc.) são ativos que apóiam a competitividade da empresa. E mesmo que uma empresa possa ser parceira de outra em uma cadeia de suprimento, elas poderão concorrer em outro mercado. Como, então, viabilizar a troca de informações sobre esses ativos?

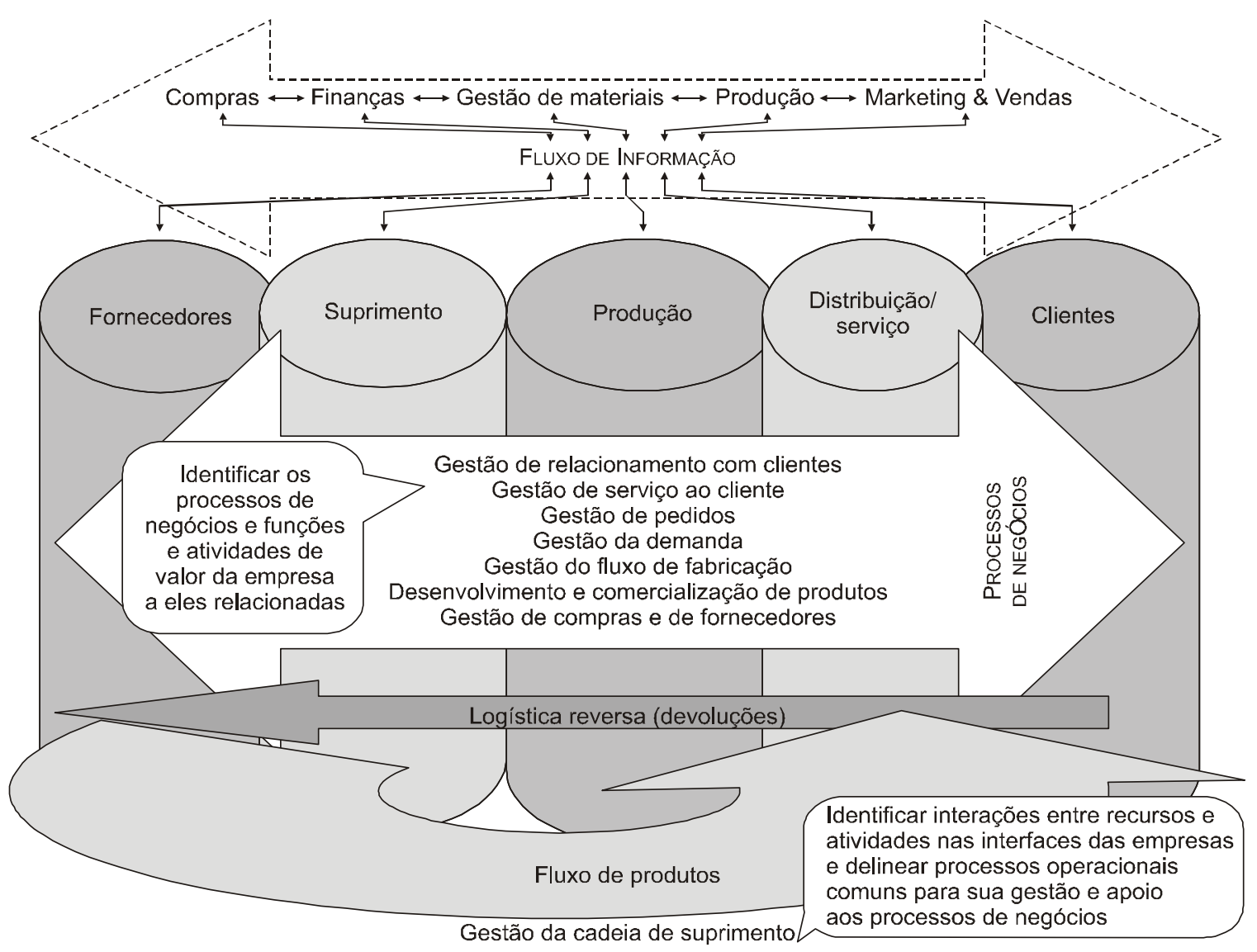

(Componentes para coordenação dos processos de negócios entre as empresas)

Planejamento e controle

Estrutura dos processos de trabalho

Estrutura para fluxo físico

Estrutura interorganizacional

Estrutura para fluxo de informações $(\mathrm{TI})$

Métodos de gestão

Estrutura de poder e liderança

Estrutura de produtos

Estrutura de riscos e recompensas

Cultura e atitude

Figura 3 - Dinâmica da cadeia de suprimento: escopo, função e instituições. Fonte: Adaptada de Lambert \& Cooper (2000). 
Tabela 1 - Processos de negócios.

Gestão de relacionamento com clientes: identificação de mercados-alvo e desenvolvimento e implementação de programas com clientes-chave

Gestão de serviço ao cliente: posicionamento do pedido quanto à produção e à expedição

Gestão da demanda: sincronização entre o fluxo de materiais e produtos e a demanda do cliente para redução da variabilidade

Gestão de pedidos: monitorar entrega do pedido no prazo e com exatidão de conteúdo

Gestão do fluxo de fabricação: sincronizar compras de materiais com necessidades de fabricação, buscando flexibilização produtiva e adequação da carteira de produtos

Gestão de compras e de fornecedores: administração de fornecedores, categorizando-os para tratamento diferenciado

Desenvolvimento e comercialização de produtos: integração de clientes e fornecedores no desenvolvimento de produtos para atender ao mercado

Para Schendel (1995), uma forma é possibilitar que rotinas sejam organizadas como processos interorganizacionais de aprendizagem. Para isso, Nohria \& Eccles (1992) consideram necessário que a coordenação de redes industriais determine o papel e a ação de cada um de seus participantes nesses processos. Espera-se com isso entender o posicionamento de cada um no desenvolvimento dos demais nas cadeias em que são parceiras e nos mercados em que são concorrentes.

Terra (2000) pondera que a geração do conhecimento organizacional, segundo a abordagem da Escola de Informação, considera o uso de Sistemas de Informação (SI) para aumentar o valor dos ativos intelectuais, "pois, ao contrário dos ativos físicos, estes aumentam seu valor à medida que aumenta seu uso". Esse autor apresenta, ainda, a escola comportamental como abordagem complementar para desenvolver o conhecimento organizacional, tendo-o por processo dinâmico e social, envolvendo mudanças de habilidades e aquisição de know-how.

Os SIs apóiam a comunicação entre os diferentes níveis organizacionais (hierárquicos) e áreas funcionais das empresas. Internamente à empresa, essa comunicação tem sido facilitada pela implantação de sistemas de integração de processos gerenciais (enterprise resource planning) e de sistemas de medição de indicadores de desempenho. Esses sistemas agilizam a aquisição das medidas e a constante atualização das ocorrências e, também, facilitam e ampliam a visualização para toda a empresa. A contrapartida para apoiar a coordenação de rede de empresas é incorporar sistema de troca de informação e de medição de desempenho, aceito e acessível a todos os seus participantes. A fim de que essa integração cruze as fronteiras da empresa, são necessárias práticas gerenciais para integração de fornecedores, assim como o desenvolvimento de condições ambientais para empreender ações conjuntas.

Ibarra (1992), ao analisar o contexto para interação entre empresas, propõe diferentes domínios para compreensão do relacionamento: 1 . workflow em que os canais de comunicação e troca de recursos se dão em base diária nas transações rotineiras; 2. redes de influência; em que a conexão invoca o exercício de poder, no qual são estabelecidos mecanismos de proteção e benefício mútuos; e 3. redes de amizade (friendship network ou expressive relations), nas quais a empatia e o apoio social dão suporte aos relacionamentos. Essa visão pode fundamentar a expansão do conceito de criação de conhecimento organizacional de Terra (2000), para o conceito de conhecimento interorganizacional, como sendo produzido por contato social entre pessoas das diferentes empresas, pela cooperação para troca de conhecimento tácito, pela explicitação de modelos mentais e abertura para diversidade de 
opiniões e pela construção de pensamento sistêmico sobre a cadeia de suprimento.

Ragatz et al. (1997) apontam algumas práticas e condições ambientais para integração de fornecedores no desenvolvimento de novos produtos (DNP) (Tabela 2) que podem ser complementadas com outras atividades para atingir os três domínios de Ibarra (1992).

\subsubsection{Estratégia da cadeia de suprimento e desenvolvimento de capacitações}

A escolha de um tipo de estratégia competitiva é apontada por Porter (1986), como sendo baseada em processos interativos da empresa com mercados, indústrias, segmentos e outras empresas. Essa interação se dá em diferentes níveis de decisão e de competências internas responsáveis pela formulação de estratégia. $\mathrm{O}$ processo de formulação de estratégia pode ser visto sob duas perspectivas: a de desenvolvimento de visão estratégica e a de recursos da firma.

O desenvolvimento de visão estratégica privilegia o entendimento da relação empresa-indústria. Busca-se capacitação para análise do setor ou segmento produtivo de atuação da empresa, assim como de seus fornecedores e clientes. A estratégia da empresa é estabelecida segundo as características dinâmicas e as tendências desses setores e segmentos para definir o posicionamento da empresa no mercado. O planejamento estratégico prevê o desenvolvimento de capacitação da firma para integração das funções organizacionais - segundo critérios de priorização das funções críticas para o negócio da empresa e para integração com seus fornecedores e clientes. A relevância das funções críticas, por outro lado, é o que fundamenta a segunda perspectiva para formulação de estratégia: o desenvolvimento de recursos na firma.

A abordagem de recursos da firma entende que cada empresa tem um portfólio de recursos (físicos e financeiros) organizacionais (sistemas administrativos e cultura) e intangíveis (competências e habilidades, conhecimento, imagem, marca e patentes).

É com base nos recursos disponíveis que se consolidam as vantagens competitivas identificadas pela visão estratégica da empresa. As oportunidades vislumbradas pelo conhecimento do mercado poderão ser exploradas segundo os recursos que a empresa pode mobilizar e organizar.

Tabela 2 - Condicionantes para integração de fornecedores.

\begin{tabular}{|c|c|}
\hline Práticas gerenciais & Fatores ambientais \\
\hline Desenvolvimento conjunto de sistemas de medição de desempenho & \multirow{4}{*}{$\begin{array}{l}\text { Familiaridade com a } \\
\text { capacitação do fornecedor } \\
\text { antes de integrá-lo ao } \\
\text { projeto }\end{array}$} \\
\hline Ligação por sistemas de informação (EDI, CAD/CAM, e-mail) & \\
\hline Comunicação aberta e direta nas diferentes funções das empresas & \\
\hline Compartilhar ativos físicos (instalações e/ou equipamentos) & \\
\hline $\begin{array}{c}\text { Participação de pessoal do fornecedor na equipe de projeto do comprador/ } \\
\text { fabricante }\end{array}$ & $\begin{array}{l}\text { Forte apoio da gerência } \\
\text { superior da empresa }\end{array}$ \\
\hline Participação de pessoal do fornecedor em funções na empresa fabricante (teste & \multirow{3}{*}{$\begin{array}{l}\text { Consenso sobre a seleção } \\
\text { correta do fornecedor a ser } \\
\quad \text { integrado }\end{array}$} \\
\hline de protótipo, testes de produção ou para solução de problemas específicos) & \\
\hline Compartilhar tecnologias & \\
\hline $\begin{array}{c}\text { Compartilhar treinamento e educação (gestão e liderança, melhoria contínua, } \\
\text { técnicas de solução de problemas, trabalho em equipe, custeio baseado em } \\
\text { atividades, legislação e regulamentações) }\end{array}$ & \multirow[t]{3}{*}{$\begin{array}{l}\text { Forte apoio da gerência } \\
\text { superior da empresa } \\
\text { compradora }\end{array}$} \\
\hline Práticas e procedimentos para desenvolvimento de confiança mútua & \\
\hline Acordos formalizados para compartilhar riscos e benefícios & \\
\hline
\end{tabular}


Farina (1999) entende que a ação estratégica depende da capacidade da firma em alterar o ambiente competitivo e a estrutura do mercado, induzindo padrões de concorrência a seu favor, moldando o ambiente institucional de atuação da empresa. Esse ambiente é moldado pela compreensão das instituições legais vigentes e dos padrões de concorrência, estrutura dos mercados e características da demanda. Esses elementos devem ser considerados no processo de formulação das estratégias da firma. Hall \& Andriani (1998) reconceituam a visão de recursos da firma no contexto de cadeia de suprimento como o processo de gestão de recursos intangíveis para promoção de capacitação das empresas participantes, como exposto no Quadro 3.

\section{Gestão da mudança em cadeias de suprimento}

O processo de transformação da rede de empresas é aqui nomeado de dinâmica (inter) orga- nizacional. Uma mudança em uma atividade ou em um processo e/ou produto necessariamente incorrerá em transformações a jusante e/ou a montante nas atividades/processos relacionados. Entende-se que, assim, surge uma nova arquitetura interorganizacional, em que são criadas novas estruturas para os processos de decisão sobre locação e uso da capacidade produtiva na rede logística (recursos tecnológicos) e de coordenação (gestão das atividades para uso efetivo de recursos transacionados na cadeia de suprimento).

Os mecanismos de coordenação ocorrem em diferentes níveis de interação entre as empresas, expostos no Quadro 4, com suas respectivas metas, segundo Gonçalves (1990).

Esse autor argumenta que os mecanismos de coordenação entre as empresas, e de articulação entre diferentes níveis em que elas se relacionam, servem para integrar os três sistemas: decisão, ação e informação, que suportam as interações interorganizacionais (Tabela 3).

\section{Quadro 3 - Capacitação a ser desenvolvida no contexto de cadeia de suprimento.}

\begin{tabular}{|c|c|}
\hline $\begin{array}{c}\text { Capacitação regulatória: levantamento } \\
\text { das entidades legais, dos direitos de } \\
\text { propriedade e autorais, de patentes, } \\
\text { marcas, contratos, licenças, sistemas } \\
\text { proprietários de operações e de } \\
\text { informações e banco de dados }\end{array}$ & $\begin{array}{c}\text { Capacitação de posicionamento: desenvolvimento dos } \\
\text { ativos: reputação da empresa ou de produtos, } \\
\text { configuração da cadeia de valor, rede logística } \\
\text { (fornecimento e distribuição), complexidade da estrutura } \\
\text { de decisão, sistemas instalados para operação e circulação } \\
\text { de informação (ERP, EDI, etc.) e pesquisas de mercado }\end{array}$ \\
\hline $\begin{array}{c}\text { Capacitação funcional: qualificação } \\
\text { individual e ou de equipes, conhecimento } \\
\text { sobre "como fazer", difusão do } \\
\text { conhecimento e absorção do } \\
\text { conhecimento }\end{array}$ & $\begin{array}{c}\text { Capacitação cultural: características organizacionais, } \\
\text { percepção de padrões de qualidade a serem disseminados. } \\
\text { Habilidade das empresas em gerenciar mudanças, adotar } \\
\text { inovações, montar equipes de trabalho, responder a } \\
\text { desafios e definir padrão de serviço }\end{array}$ \\
\hline
\end{tabular}

Quadro 4 - Níveis de arquitetura interorganizacional. Adaptado de Golçalvez (1990).

Institucional: equilíbrio de poder na definição de metas e condições para estabelecer acordos

Relacional: comprometimento das empresas e busca de sinergia na formulação de problemas e resolução de conflitos de interesses e definição das normas para transação/relacionamento

Processual: definição conjunta de procedimentos para funcionamento da rede de empresas Operacional: busca de eficiência técnica nos processos operacionais (produtivos e logísticos) 
Tabela 3 - Sistemas envolvidos nas interações entre as empresas.

\begin{tabular}{cc}
\hline Sistema & Função \\
\hline De decisão & Envolve a identificação de valores e normas de conduta na exploração das oportunidades \\
para melhoria de desempenho
\end{tabular}

Para isso são necessários mecanismos de articulação entre os diferentes níveis de organização da empresa (estratégico, tático e operacional) e nos diferentes níveis de interface entre as empresas (institucional, relacional, processual e operacional) para alinhamento entre estratégia e desempenho, internos à empresa, e direcionamento estratégico da cadeia de suprimento e do desempenho conjunto das empresas.

O propósito de criar estrutura para acompanhar o processo de transformação da rede industrial é a criação de linguagem comum e de mesma perspectiva entre os membros da cadeia de suprimento, a fim de desenvolver capacitações em aspectos regulatórios, culturais, de funcionamento e posicionamento das empresas. $\mathrm{O}$ desenvolvimento dessas capacitações é sujeito a processos gerenciais mostrados na Tabela 4, como proposto em Hall \& Andriani (1998).

\subsection{Arquitetura interorganizacional da cadeia de suprimento}

O Quadro 5 traz a proposta deste trabalho para gerenciar a transformação da cadeia de suprimento, nos quatro níveis considerados por Gonçalves (1990). Esse módulo, agregado ao modelo de GCS, de Lambert \& Cooper (2000), tem por função criar capacitação às empresas submetidas à inovação (principalmente quando esta é proposta por outra, que tem o comando na trajetória de mudança). Esta proposta atende a um dos pressupostos destacados por Green \& Santos (1991) no conceito de rede de empresas: a criação de sinergia para consecução de meta estabelecida em conjunto.

Um dos aspectos-chave na GCS é a cooperação entre as empresas na organização de diferentes funções (logística, marketing, desenvolvimento de produto, sustentabilidade, etc.).

\section{Tabela 4 - Gestão do conhecimento no contexto de cadeia de suprimento. Adaptada de Hall \& Andreani (1998).}

\begin{tabular}{cc}
\hline Processo de: & Meta \\
\hline Externalização & $\begin{array}{c}\text { Codificação do conhecimento tácito e definição de formas eficientes para sua difusão } \\
\text { Comunicação explícita do conhecimento a ser difundido, fazendo uso de } \\
\text { linguagem comum }\end{array}$ \\
$\begin{array}{c}\text { Internalização } \\
\text { Socialização }\end{array}$ & $\begin{array}{c}\text { Absorção do conhecimento na rotina das empresas } \\
\text { Transformação }\end{array}$ \\
$\begin{array}{c}\text { Absorção das mudanças pelos atores da cadeia de suprimento e estabelecimento de gestão } \\
\text { da rotina das operações de fornecimento/distribuição diante das mudanças adotadas }\end{array}$ \\
\hline
\end{tabular}


Quadro 5 - Arquitetura interorganizacional da cadeia de suprimento.

\begin{tabular}{|c|c|c|c|c|}
\hline Nível & Papel & Racionalidade & Compartilha & Interdependência tecnológica \\
\hline Institucional & $\begin{array}{l}\text { Preservar a } \\
\text { identidade e a } \\
\text { legitimidade } \\
\text { das empresas }\end{array}$ & $\begin{array}{l}\text { Consciência da } \\
\text { dependência de } \\
\text { cada empresa }\end{array}$ & Valores & $\begin{array}{l}\text { Consciência das oportunidades } \\
\text { Avaliação da capacidade de absorção } \\
\text { e redefinição, em todos os níveis, dos } \\
\text { processos e dos papéis de cada } \\
\text { organização, a fim de manter a } \\
\text { identidade e a coerência das } \\
\text { estratégias das organizações } \\
\text { componentes da rede } \\
\text { Análise da conectividade resultante } \\
\text { das inovações }\end{array}$ \\
\hline $\begin{array}{l}\text { Relacional } \\
\text { (processos de } \\
\text { negócios) }\end{array}$ & $\begin{array}{l}\text { Articular e } \\
\text { solucionar } \\
\text { conflitos }\end{array}$ & $\begin{array}{l}\text { Sinergia de } \\
\text { interesses }\end{array}$ & $\begin{array}{l}\text { Aprendizagem } \\
\text { tecnológica e } \\
\text { organizacional }\end{array}$ & $\begin{array}{l}\text { Conhecimento dos limites das } \\
\text { empresas } \\
\text { Desenvolvimento de capacitação para } \\
\text { atender às inovações } \\
\text { Planejamento colaborativo para } \\
\text { melhoria do desempenho nas } \\
\text { diferentes funções (pertinentes) }\end{array}$ \\
\hline $\begin{array}{l}\text { Processual } \\
\text { (estrutura) }\end{array}$ & $\begin{array}{c}\text { Compatibilizar } \\
\text { procedimentos } \\
\text { e normas } \\
\text { operacionais }\end{array}$ & $\begin{array}{c}\text { Cooperação na } \\
\text { busca de } \\
\text { sinergias } \\
\text { operacionais }\end{array}$ & $\begin{array}{l}\text { Estratégias de } \\
\text { operações } \\
\text { Conectividade } \\
\text { nos processos }\end{array}$ & $\begin{array}{c}\text { Noção do impacto das inovações } \\
\text { Adequação a projetos de processos } \\
\text { Gestão de recursos e atividades entre } \\
\text { as empresas } \\
\text { Redesenho dos ciclos de atividades e } \\
\text { dos processos }\end{array}$ \\
\hline $\begin{array}{l}\text { Operacional } \\
\text { (componentes } \\
\text { de gestão) }\end{array}$ & $\begin{array}{c}\text { Produzir } \\
\text { utilidades de } \\
\text { valor/tempo e } \\
\text { lugar }\end{array}$ & $\begin{array}{l}\text { Convergência } \\
\text { de esforços } \\
\text { Conectividade } \\
\text { entre atividades }\end{array}$ & $\begin{array}{l}\text { Fluxos de } \\
\text { agregação de } \\
\text { valor na troca } \\
\text { dos recursos }\end{array}$ & $\begin{array}{l}\text { Eficiência nas interfaces do fluxo de } \\
\text { produtos }\end{array}$ \\
\hline
\end{tabular}

Outro aspecto é o tipo de ligação estrutural entre as empresas (transações via mercado, contratuais, joint venture ou outro tipo de aliança estratégica), o qual define o ambiente de consulta e influencia o processo de tomada de decisão sobre os esforços funcionais empreendidos.

A proposição de arquitetura organizacional é acomodar as empresas sujeitas a mudanças tecnológicas e conectadas por processos de negócios definidos por relacionamentos de longo prazo. Nessa estrutura há ações colaborativas entre as empresas para definir características do produto e/ou serviço criado na cadeia de suprimento e de plataforma comum para ação colaborativa. O escopo de atuação da plataforma depende da meta de mudança no produto/serviço e está associada à análise da natureza da inovação (incremental e/ou radical) e do conhecimento necessário para difusão da inovação.

A interação entre as empresas se dá em diferentes níveis: a) institucional (delineamento de políticas regulatórias para apoiar adoção de novas tecnologias); b) relacional (construção de relacionamentos para difusão de tecnologia); c) processual (compartilhamento de conhecimento dos processos); e d) operacional (esforços conjuntos para eficiência das operações).

Em cada nível são estabelecidos mecanismos de coordenação e práticas gerenciais para efetivar a cooperação entre as unidades de negócios. 
As estratégias para conduta em cada nível de interação são dependentes e cumulativas, conforme as condições ambientais para desenvolver a capacitação das empresas. As decisões em comum dependem da fase de evolução do relacionamento entre as empresas e influenciam as decisões nos demais níveis.

O Quadro 6 formaliza a aplicação do modelo em uma situação de mudança de produto e sistema de entrega, prescrevendo o necessário para o desenvolvimento da capacitação.
Essa proposta objetiva desenvolver sinergia entre as empresa, a fim de acomodar mudanças em produto e processo. Para isso, dois aspectos são considerados pilares fundamentais: a) desenvolvimento da consciência da dependência mútua entre as empresas participantes de cadeias de suprimento e b) clareza na definição do papel de cada uma das empresas no processo de agregar valor, retratado nos fluxos produtivos e logísticos da cadeia de suprimento.

\section{Quadro 6 - Desenvolvimento de capacitação das empresas com mudança no produto.}

\begin{tabular}{|c|c|c|}
\hline $\begin{array}{l}\text { Níveis de } \\
\text { interação }\end{array}$ & Atributos a serem desenvolvidos & $\begin{array}{c}\text { Meta/ } \\
\text { ESTRUTURA DE DECISÃO }\end{array}$ \\
\hline Institucional & $\begin{array}{l}\text { Configuração do produto e da rede } \\
\text { Imagem do produto/segmento de mercado/preço } \\
\text { Legislação/requisitos para desenvolvimento do produto } \\
\text { Base tecnológica para desenvolvimento/grau de } \\
\text { inovação/tempo de lançamento do produto }\end{array}$ & $\begin{array}{c}\text { Proteção dos direitos } \\
\text { Sustentação da vantagem pela inovação } \\
\text { Exploração e prospecção tecnológica } \\
\text { Definição de responsabilidades de } \\
\text { acordo com competências } \\
\text { DECOMPOSIÇÃO }\end{array}$ \\
\hline Relacional & $\begin{array}{c}\text { Projeto do produto na cadeia de suprimentos } \\
\text { Capacitação de posicionamento/projeto do produto e de } \\
\text { processos para fabricação (co-produção) e para } \\
\text { disponibilizar o produto no mercado } \\
\text { Esforços conjuntos para lançamento do produto } \\
\text { Compartilhar informação para planejamento } \\
\text { colaborativo }\end{array}$ & $\begin{array}{c}\text { Capacitação cultural } \\
\text { Adoção/difusão de tecnologia apropriada } \\
\text { ao produto e ao sistema de entrega } \\
\text { Desenvolvimento de estrutura } \\
\text { mercadológica } \\
\text { MULTIFOCAL EM REDE }\end{array}$ \\
\hline Processual & $\begin{array}{c}\text { Formação da rede produtiva/logística } \\
\text { Capacitação funcional/sistemas de qualidade, sistemas } \\
\text { de respostas rápidas para atendimento de pedidos } \\
\text { Habilidade para variar especificação do produto, } \\
\text { volume de produção } \\
\text { Compartilhar informação para cooperação na } \\
\text { programação da produção }\end{array}$ & $\begin{array}{l}\text { Padrão do serviço de entrega e de } \\
\text { qualidade/especificação do produto } \\
\text { Gestão da demanda e do fluxo produtivo } \\
\text { e de distribuição para seu atendimento } \\
\text { MULTIFOCAL EM REDE }\end{array}$ \\
\hline Operacional & $\begin{array}{l}\text { Otimização dos processos da cadeia de suprimentos } \\
\text { Monitorar o desempenho dos ciclos de entrega } \\
\text { Compartilhar informação para controle das operações }\end{array}$ & $\begin{array}{l}\text { Monitorar qualidade e nível de serviço } \\
\text { Atender aos pedidos } \\
\text { MULTIFOCAL SIMPLES }\end{array}$ \\
\hline
\end{tabular}




\section{Considerações finais}

Lambert \& Cooper (2000) vêem a gestão da cadeia de suprimento sob lógica técnica, ocupando-se da administração de processos de negócios e de ciclos de atividades. O modelo proposto para gestão tecno-organizacional analisa as transformações que se passam na rede de empresas, tendo por principal função criar capacitação às empresas submetidas à inovação, principalmente quando ela é proposta por outra, que tem o comando na trajetória de mudança. As empresas subordinadas têm, assim, como acompanhar as inovações que ocorrem no espaço de produção-circulação em que atuam. Essa proposta atende a um dos pressupostos destacados por Green \& Santos (1991) no conceito de empresa-rede (rede de empresas): a criação de sinergia entre as organizações que constituem redes de empresas.

Gonçalves (1990), a exemplo de Lundgren (1995), compreende, ainda, que a transformação da rede é condicionada pelo ambiente institucional, em que interagem vetores de poder, com diferentes referências setoriais e forças competitivas. Esse condicionante se apóia em Dosi et al. (1988), que afirmam que a difusão de um paradigma tecnológico ou de um projeto dominante depende, em geral, da natureza e do interesse de "plataformas institucionais" e de agências públicas. A inovação tecnológica e a exploração de suas oportunidades necessitam de intervenção institucional, seja pública ou privada, para definir políticas de incentivo a adoção de novas tecnologias.

Entende-se que Lambert \& Cooper (2000) analisam a gestão da cadeia de suprimento sem considerar o desequilíbrio de poder entre seus participantes. A gestão tecno-organizacional tem por objetivo gerenciar as mudanças, considerando o desenvolvimento da capacitação da empresa para atuar na cadeia de suprimento transformada. Seu objetivo é viabilizar a implementação dessas mudanças, quanto à velocidade na difusão de inovações tecnológicas e/ou organizacionais, a fim de preservar os interesses das empresas parceiras submetidas/subordinadas a quem comanda o processo inovativo.

Também é necessário incentivar o desenvolvimento de sinergia entre empresas de mesmo setor ou de setores diferentes de um país, porém com interesses comuns, a fim de aumentar o poder de barganha para defesa conjunta diante da globalização produtiva ou buscar meta definida (como, por exemplo, o desenvolvimento sustentável). É nesse sentido que se considera a ampliação de escopo para gestão da cadeia de suprimento, saindo do nível operacional/processual e estendendo-se para os níveis institucional e relacional, no caso de gestão tecnológica da cadeia de suprimento.

\section{Referências Bibliográficas}

ANAND, K. S.; MENDELSON, H. Information and organization for horizontal multimarket coordination. Management Science, v. 43, n. 12, p. 16091627, 1997.

BECHTEL, C.; JAYARAM, J. Supply chain management: a strategic perspective. The International Journal of Logistics Management, v. 8, n. 1, p. 15-34, 1997.

CHOPRA, S.; MEINDEL, P. Gerenciamento da cadeia de suprimentos. São Paulo: Prentice-Hall, 2003. $465 \mathrm{p}$.

CHRISTOPHER, M. Gerenciamento da cadeia de suprimento. São Paulo: Pioneira, 1997. 240 p.
DOSI, G.; FREEMAN, C.; NELSON R.; SILVERBERG, G.; SOETE, L. (Ed.). Technical change and economic theory. London: Pinter, 1988.

FARINA, E. M. Competitividade e coordenação de sistemas agroindustriais: um ensaio conceitual. Gestão e Produção, v. 6, n. 3, p. 147-161, 1999.

FISHER, M. What is the right supply chain for your product? Harvard Business Review, v. 75, n. 2, p. 105-116, mar./abr. 1997.

GARCÍA-DASTUGUE, S. J.; LAMBERT, D. M. Internet-enable coordination in the supply chain. Industrial Marketing Management, n. 20, p. 251263, 2003. 
GONÇALVES, M. Contribuição ao estudo dos processos de interdependência organizacional e tecnológica. 1990. Tese (Doutorado) - Escola Politécnica da Universidade de São Paulo, São Paulo.

GREEN, R. H.; SANTOS, R. R. Economía de rede y reestructuración del sector agroalimentario. Mudanza técnica y reestructuración del sector agroalimentario. Consejo Superior de Investigaciones de Espanha, Madri, 1991. p. 33.

HAGELAAR, G.; VAN DER VORST, J. G. A. J. Environmental supply chain management: using life cycle assessment to structure supply chains. International Food and Agribusiness Management Review, n. 4, p. 399-412, 2002.

HALL, R.; ANDRIANI, P. Management focus: analysing intangible resources and managing knowledge in a supply chain context. European Management Journal, v. 16, n. 6, p. 685-697, 1998.

HANDFIELD, R.; NICHOLS, E. Introduction to supply chain management. New Jersey: Prentice Hall, 1999.

HEIKKILÄ, J. From supply to demand chain management: efficiency and customer satisfaction. Journal of Operations Management, n. 20, p. 747767, 2002.

IBARRA, H. Structural alignments, individual strategies, and managerial action: elements toward a network theory of getting thins done. In: NOHRIA, N.; ECCLES, G. (Eds.). Networks and organizations: structure, form and action. Boston: Harvard Business School Press, 1992. p. 165-188.

KIM, B. Coordinating an innovation in supply chain management. European Journal of Operational Research, n. 123, p. 568-584, 2000. Disponível em: 〈http://www.elsevier.com/locate/dsw>. Acesso em: 20 maio 2003.

LAMBERT, D. M.; COOPER, M. C. Issues in supply chain management. Industrial Marketing Management, n. 29, p. 65-83, 2000.

LUNDGREN, A. Technological innovation an network evolution. NewYork: Routledge, 1995.
MARQUES, I. C. Desmaterialização e trabalho. In: LASTRES, H.; ALBAGLI, S. (Orgs.). Informação e globalização na era do conhecimento. Rio de Janeiro: Campus, 1999, p. 191-202.

MESQUITA, M.; ALLIPRANDINI, D. H. Competências essenciais para melhoria contínua da produção: estudo de caso em empresas da indústria de autopeças. Gestão \& Produção, v. 10, n. 1, p. 17-33, abr. 2003.

McGEE, J.; PRUSAK, L. Gerenciamento estratégico da informação. Rio de Janeiro: Campus, 1994.

NOHRIA, N.; ECCLES, G. (Eds.). Networks and organizations: structure, form and action. Boston: Harvard Business School Press, 1992.

NOLAN, R. L.; CROSAN, D. C. Destruição criativa. Rio de Janeiro: Campus, 1996.

PETRONI, A.; PANCIROLI, B. Innovations as a determinant od supplier's roles and performance: an empirical study in the food machinery industry. European Journal of Purchasing \& Supply Management, v. 8, p. 135-149, 2002.

PORTER, M. E. Estratégia competitiva: técnicas para análise de indústrias e da concorrência. 7. ed. Rio de Janeiro: Campus, 1986.

RAGATZ, G. L.; HANDFIELD, R.; SCANNELL, T. V. Success factors for integration suppliers into new product development. Journal Product Innovation Management, n. 14, p. 190-202, 1997.

SCHENDEL, D. Technological transformation and new competitive landscape. Strategic Management Journal, v. 16, n. S1, p. 1-6, Summer, 1995.

SLACK, N. Vantagem competitiva em manufatura. São Paulo: Atlas, 1993.

SLACK, N.; CHAMBERS, S.; JOHNSTON, R. Administração da produção. 2. ed. São Paulo: Atlas, 2002.

TEECE, D. J.; PISANO, G.; SHUEN, A. Dynamic capabilities and strategic management. Strategic Management Journal, v. 18, n. 7, p. 509-533, 1997.

TERRA, J. C. C. Gestão do conhecimento: o grande desafio empresarial. São Paulo: Negócios Editora, 2000. 


\title{
REFLECTIONS ON TECHNOLOGICAL MANAGEMENT IN SUPPY CHAINS
}

\begin{abstract}
The integration of activities in the supply chain and the technologies that give them appropriate support have been specifically explored and intensely related to the new communication and information technologies (IT). This work extend this analysis to the adoption of technological innovation in the industrial network, which is related to changes in the transacted product, besides changes in the management process provided by the advances in the IT. The question offered for this reflection is: how the companies adjust this new configuration, provided by technological and organizational innovations, to the chain management? This paper presents the concept of inter-organizational architecture as being this new configuration, where new structures for the decision process of location and use of the productive capacity of the logistics network (technological resources) take place, as well as the coordination process (management of the activities for positive use of the resources transacted in the supply chain). A conceptual model for the performance of this architecture is also presented.
\end{abstract}

Key words: supply chain, technological management, organization. 